IRA-International Journal of Management \&

Social Sciences

ISSN 2455-2267; Vol.16, Issue 01 (Jan.-March, 2020)

Pg. no. 31-39.

Institute of Research Advances

http://research-advances.org/index.php/RAJMSS

QUARTERLY

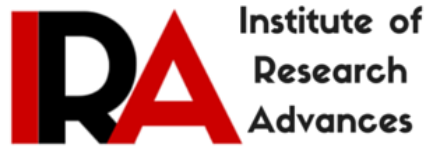

\title{
Ritual Hymns and World View of the Totola Rabhas of Kataligaon
}

\section{Bhupen Rabha}

Assistant Professor, Department of English, BBK College, Nagaon (Barpeta), Assam, India.

Type of Work: Peer Reviewed.

DOl: http://dx.doi.org/10.21013/jmss.v16.n1.p3

\section{How to cite this paper:}

Rabha, B. (2020). Ritual Hymns and World View of the Totola Rabhas of Kataligaon. IRAInternational Journal of Management \& Social Sciences (ISSN 2455-2267), 16(1), 31-39. doi:http://dx.doi.org/10.21013/jmss.v16.n1.p3

(C) Institute of Research Advances.

\section{(c)) EY-NC}

This work is licensed under a Creative Commons Attribution-Non Commercial 4.0 International License subject to a proper citation to the publication source of the work.

Disclaimer: The scholarly papers as reviewed and published by the Institute of Research Advances (IRA) are the views and opinions of their respective authors and are not the views or opinions of the IRA. The IRA disclaims of any harm or loss caused due to the published content to any party.

Institute of Research Advances is an institutional publisher member of Publishers International Linking Association Inc. (PILA-CrossRef), USA. The institute is an institutional signatory to the Budapest Open Access Initiative, Hungary advocating the open-access of scientific and scholarly knowledge. The Institute is a registered content provider under Open Access Initiative Protocol for Metadata Harvesting (OAl-PMH).

The journal is indexed \& included in WorldCat Discovery Service (USA), CrossRef Metadata Search (USA), WorldCat (USA), OCLC (USA), Open J-Gate (India), EZB (Germany) Scilit (Switzerland), Airiti (China), Bielefeld Academic Search Engine (BASE) of Bielefeld University, Germany, PKP Index of Simon Fraser University, Canada. 


\begin{abstract}
The Totola Rabhas are a community that has never lived in isolation. They are touched on all sides by other communities and ethnic groups. Therefore, cultural assimilation in the case of the Totola Rabhas is not a new phenomenon. The culture of the Totola Rabhas which is a part of Indo Mongoloid culture has contributed a lot towards the greater Assamese culture. The evolvement of a new cultural identity in the real sense of the term, the Totola Rabhas, overtime is a fact ignored by and unknown to the world. Therefore, it is of utmost necessity to study the folklore of the Totola Rabhas to understand the culture of a community not only least represented but also misunderstood. The Totola Rabhas have a very rich tradition of folklore, which has not at all been explored. They are passed down from generation to generation through word of mouth and in the long run, they have undergone a drastic change due to assimilation with people of other communities. This assimilation has enriched and added to the already existing folklore of the Totola Rabhas. The folk songs and the oral narratives of the Totola Rabhas are indeed unique in their own nature. The songs sung during various occasions are a living tradition of the Totola Rabhas. They are sung during marriages, during work, during worships, during festivals, etc. The Totola Rabhas believe in many Gods and Goddesses and they observe a variety of rituals. One such religious practice of the Totola Rabhas is the worship of Bura Bun Gohai, ie. Old Forest Deity. She is believed to be the Goddess of all things and the prosperity of the village depends entirely on her. It is, therefore, a humble attempt on the part of the Researcher to explore and document the folk songs associated with their traditional religion and belief. This paper is an attempt to explore the ritual hymns and the world view of the Totola Rabhas of Kataligaon.
\end{abstract}

Keywords: Totola Rabha, Indigenous religious practice, Bura Bun Gohai (Old Forest Deity)

\title{
Introduction
}

Totola Rabhas are a branch of the Rabhas. The Rabhas are a tribe belonging to the great Bodo family and scattered in parts of lower Assam, Kamrup district, Goalpara district, parts of West Bengal and Meghalaya. There is no distinct information about the actual origin of the Rabhas as scholars have divergent opinions regarding their place of origin. According to Major A. Playfair, the Rabhas had migrated from the Tibetan regions to the Garo-Hills and afterward spread throughout the state of Assam. Gait wrote in his 'Census Report of Assam' (1891), about the origin of the Rabhas:

"There seems to be a good idea of uncertainty as to who these people are. In lower Assam, it is asserted that they are an off-shoot of the Garos, while in Kamrup and Darrang it is thought that they are Kachari on the road to Hinduism".

Dalton (1872) states, "The Rabhas and the Hajongs of the Goalpara District are also branches of the Kachari race and connected with the Garos."

Though there are diversified opinions about the origin of the Rabhas, ethnic affinities establish them to be a member of the great Mongolian stock.

The Rabha population shows certain divisions within their communities after the name of their chieftain and this way they identify their clans, which are nothing but seven different branches of the Rabhas. These branches are:
1. Rangdani
2. Maitori
3. Dohari
4. Pati
5. Cunga
6. Bitalia
7. Totola
8. Koch Rabha 
The Rongdani, Maitori and the Koch Rabhas are the major socio-linguistic groups. They are maintaining their inherent language and culture in comparison to the other minority groups. Efforts are being made recently to codify the Rongdani dialect as the standard language of the Rabhas as a whole.

The Totola Rabhas are scattered on the Northern side of the river Brahmaputra, mainly in Baksa, Chirang, Sonitpur, Darrang, and Udalguri districts. The sad part of this little known tribe is that they are scattered mostly in small groups among other tribes and communities and have lost most of their cultural identities including their language, culture, and traditional dress. Bora (2013) says that the Rabhas maybe different from the Bodos but their ways and culture are almost the same. He further notes that the Rabhas may be thought to have mingled with the Garos but the Rabhas have managed to preserve their own cultural identity. Totola Rabhas are one such community that has lost its own identity with the passage of time but at the same time has acquired a unique identity of its own very near to both the neighbouring Bodos as well as the Assamese. Apart from Rongdani and Maitori Rabhas, the Pati and Totola Rabhas, have almost dissolved themselves amidst either the Assamese or the Bodos. Linguistically they have failed to keep their separate identity. They have close contact with the neighbouring Assamese speaking and Bodo speaking population from time immemorial and consequently, they are highly influenced by these populations of the Brahmaputra valley. Thus, their social life and social customs have gained a different colour, which has now been distinct and quite different from the remaining Rabha clans. At present, their common media of conversation is a broken variety of Assamese mixed with Rabha and Boro words and expressions. There has been an excellent cultural synthesis in the evolvement of the Totola Rabhas.

Today, the Totola Rabhas are the least represented among all the other clans of the Rabhas. In fact, in many of the classifications of the Rabha clans, Totola Rabhas are not even mentioned. They are thought to have undergone not only a cultural change but have also assimilated with their neighbouring communities. This is partly true as Totola Rabhas have undergone a change as regards their cultural identity but at the same time, they have acquired a unique identity, an identity very different from the Assamese as well as the Bodos. They have the characteristics of the Bodos regarding their food habits and way of life and at the same time, they have adopted the language of the Assamese mixed with Bodo words and also words that are independently developed. In fact, some of the Totola Rabhas have adopted Bodo language as their mother tongue.

The Totola Rabhas are a community that has never lived in isolation. They are touched on all sides by other communities and ethnic groups. Therefore, cultural assimilation in the case of the Totola Rabhas is not a new phenomenon. The culture of the Totola Rabhas which is a part of Indo Mongoloid culture has contributed a lot towards the greater Assamese culture. The evolvement of a new cultural identity in the real sense of the term, the Totola Rabhas, with the passage of time is a fact ignored by and unknown to the world. Therefore, it is of utmost necessity to study the folklore of the Totola Rabhas to understand the culture of a community not only least represented but also misunderstood.

The Totola Rabhas have a very rich tradition of folklore, which has not at all been explored. They are passed down from generation to generation through word of mouth and in the long run, they have undergone a drastic change due to assimilation with people of other communities. This assimilation has enriched and added to the already existing folklore of the Totola Rabhas, thus "revealing the thought processes, the hopes and fears, ideas and primitive philosophies of our remote ancestors, as well as the sudden or gradual changes in all these things affected by the changing conditions of material life" (Hole, 1944-45).

The folk songs and the oral narratives of the Totola Rabhas are indeed unique in their own nature. The songs sung during various occasions are a living tradition of the Totola Rabhas. They are sung during marriages, during work, during worships, during festivals, etc. The Totola Rabhas believe in many Gods and Goddesses and they observe a variety of rituals. One such religious practice of the Totola Rabhas is the worship of Bura Bun Gohai, ie. Old Forest Deity. She is believed to be the Goddess of all things and the prosperity of the village depends entirely on her. She is all-powerful and there have been instances where people have received boons from her. She is considered to be all-merciful and kind at the same time. People believe that their wishes are fulfilled once they ask it from 'Mother Bura Bun Gohai'. Many childless couples have received the blessings of 'Bura Bun Gohai' in the form of their sons and daughters. They are so grateful to her that they now take it as a 
duty to offer prayers and offerings to her every year. There are many families who conduct the puja at their home and the Gohai is brought to the very steps of their household accompanied by the beating of big drums and trumpets. It was during the worship of Bura Bun Gohai that a song was sung but at the moment the song is just played on a musical instrument known as kahal. The song has been long lost.

It is, therefore, a humble attempt on the part of the Researcher to explore and document the folk songs associated with their traditional religion and belief.

\section{Area and Methods}

The present paper is based on the fieldwork done in the Totola Rabha village of 2 No. Kataligaon (Rabha Supa) situated $3 \mathrm{kms}$ from Mushalpur town. With 75 families (396 persons in all), the villagers of 2 No. Kataligaon (Rabha Supa) is now a mixed population; as most of the villagers, i.e. the mothers and wives, are from different communities including Boros, Nepalis, Karbis, Assamese and Garos, of which the Boros are a majority. Inter caste marriage is a common sight that may be due to lesser contact with people of their own kind. The village itself has diversity in language due to the fact that it is bounded by Bodo villages on one side and the Assamese on the other. The ones nearer to the Bodo village speak fluent Bodo and the others speak the dialect spoken by the Assamese population living nearby. There's also a common language spoken but that too is a mixture of Assamese and Bodo.

Both primary and secondary data were to be used for the purpose.

- To collect primary data the Researcher used ethnographic research methods and visited the village of 2 No kataligaon and recorded songs (no longer sung) that were, in earlier days, sung during the offerings to Bura Bun Gohai, using recorders (audio or video available in a Mobile phone) and field notes were prepared.

- To collect secondary data the Researcher accessed secondary sources including documented perspectives like books, souvenirs, and journals.

\section{Objective}

To study ritual hymns and the world view of the Totola Rabhas

\section{Findings and Discussion}

When the whole of Assam is busy in their preparations for the New Year starting with Bohag Bihu, the only festival which is celebrated by every resident of Assam irrespective of their religion, caste and creed, during a time when most of the Indian states celebrate what they call Baisakh, the first month of the Indian calendar; the Totola Rabhas of 2 no. Kataligaon (Rabha Supa) in Mushalpur, the district headquarter of Baksa (Assam, India), are gearing up to pay their homage to Bura Bun Gohai, the Goddess of all things.

The one Goddess, apart from the many Hindu Gods and Goddesses the Totola Rabhas of Kataligaon believe in, is 'Bura Bun Gohai' that can be exactly translated into 'Old Forest Goddess'. She is worshipped only in this village but she has many believers scattering from the Assamese to the Bodos far and wide. She is believed to have many sisters of which one is in Laphakuchi; a Totola Rabha village situated $7 \mathrm{~km}$ away from kataligaon. She is believed to be all-powerful and the prosperity of the village depends entirely on her. There have been instances where people have received boons from her. She is considered to be all-merciful and kind at the same time. People believe that their wishes are fulfilled once they ask it from 'Mother Bura Bun Gohai'. Many childless couples have received the blessings of 'Bura Bun Gohai' in the form of their sons and daughters. They are so grateful to her that they now take it as a duty to offer prayers and offerings to her every year. There are many families who conduct the puja at their home and the Gohai is brought to the very steps of their household accompanied by the beating of big drums and trumpets. This gives light to the god-fearing mind of the village folk. 
The puja is held during the time of Bohag Bihu, the festival celebrated to welcome the New Year in Assam. This starts sometime between $13^{\text {th }}$ and $14^{\text {th }}$ of April every year. The day the people of Assam take their cows and buffaloes to the river to bathe while observing some ceremonial practices, the girls in the village wash the handkerchiefs used in the previous years. Before the readers get confused, let me describe the image used to represent the deity. Handkerchiefs that the devotees have offered before to the Goddess are tied to threads which are then tied to a bamboo stick of 6 to $7 \mathrm{ft}$. long. This is done ceremonially. The researcher will discuss those in greater detail as and when it occurs during the description of the actual practice step by step. As for now, one can imagine the Deity to be in the shape of a Christmas tree covered with handkerchiefs instead of leaves.

The handkerchiefs that were washed in the morning get clean and dry towards the evening. Sometime during the day, gram is soaked in water and the village priest gets the offerings ready with the help of the village halmaji, the person appointed as the village announcer. The offerings include bananas, coconut and also fruits that are readily available during the time. A group of boys go to the bamboo grove of any household and cut a suitable bamboo of 6 to $7 \mathrm{ft}$ long. They clean the bamboo, wash it with water, tulsi water and then bathe it with milk. The milk is often collected by the halmaji but it may also be offered by anyone in the village. The village committee bears all the expenses required for the puja. The washed bamboo is then rubbed with mustard oil. The boys who take the responsibility of doing all these works have to take bath and wear new gamchas, a traditional loin cloth. They use new bihuwans, a type of Assamese towel used as scarf, to wrap round their necks or to tie round their waists. On the one side, the priest assisted with younger boys gets ready with the offerings, while on the other hand, the older boys are busy with tying the handkerchiefs to 'awa huta', a kind of thread and then to the bamboo stick. All this while two strong man play the drum to the accompaniment of a trumpet called 'kahal' and 'tal', kinds of plate smashed against each other to make a kind of noise that sounds 'khang' 'khang'. The words khang, khang in Totola Rabha literally means to eat, to eat. This is the one sound that the children of the village are afraid of. The elders make them quiet by telling them that they will be eaten if they are naughty. There is a sequence for the drum beating. There are songs but they are not sung any longer. The trumpet ' $k a h a l$ ' has a typical sound that seems to be very sad. The tune of the kahal represents the song. Any village folk would know of the rituals going on at the moment on hearing the sound of the kahal, the drums and the taals for every step in the offerings/ritual is accompanied by different beating and trumpeting. Late Phacha Ram Rabha, was initially very good at playing the trumpets but later when he lost all his teeth due to so called witchcraft on the part of folks from another village, he made the sound of the trumpet using his own voice.

The sound of drums and trumpets during the offering brings almost all the villagers to the Gohai ghar, the village temple of Bura Bun Gohai. Every household take their food earlier than their usual time least they should miss the so called - 'Dohor Kasawa' which can be translated into 'decoration of the dohor'. The dohor refers to the Christmas-tree shaped Gohai. Four clumps of long artificial hair called 'Kola Songor' are tied at the tip, second a little lower, and the other two clumps somewhere between the handkerchiefs at equal lengths below. The tip of the bamboo is now fixed to a pointed metalled cap called 'sula'. This gives the appearance of a female wearing a cap. Mustard oil is applied to all the four Kola Songors just as we apply to our hair.

A spot just outside the Gohai ghar is chosen for the Dohor. The spot is cleaned and a lump of mud is plastered to the ground to form a small platform which is then rubbed clean by mud and water. Adjacent to the platform a hole is dug and a washed bamboo of a height enough to hold the dohor in place is planted firmly. An Assamese 'bota', usually used for offering bettle nut to guests is placed on the platform. A handkerchief is placed on the bota and the dohor is gently erected in it with a rope tied to the planted bamboo to hold it in place.

Many villagers from far and wide bring their offerings to the Gohai. It is said that people who have actually experienced the blessings of Bura Bun Gohai usually bring offerings to the God. Many a times, the village folk promise to bring their offerings if their prayers are answered. This is how the devotees are growing every year. Tips of five banana leaves known as 'agloti' are placed below the platform. Five small barks the size of an adult hand cut out of banana plant, called 'donas' are placed on the aglotis. Offerings of gram mixed with pulses, ginger, coconut, salt, rice grains are placed in each bark. Five bananas are placed on the offerings in each of them. Earthen lamps are lighted and incense sticks are burned near the offerings. On the sideline, offerings brought by the villagers are kept. Prashad is usually arranged for the whole village folk. All this while, the 
beatings of drums accompanied by the sound of trumpet and taals have been going on. The priest offers his prayers and sprinkles tulsi water on the offerings and also on the villagers who have gathered there. The music goes on and on. Every one kneels and bows before the dohor, the priest says a prayer and ends in the following words - 'Joi aai Bura Bun Gohaik sinti hori bol, hori bol, hori bol.' And then everyone chants 'hori bol, hori bol, hori bol.' Prashad is then distributed among the devotees. The children carry bowls from home to receive the prashad. Banana leaves are also distributed among the villagers.

It is to be noted that the music played is rhythmic and goes along with the ritual towards the end. The otherwise loud music changes to a soft one when it's the priest's turn to chant his prayers. It comes to a sudden stop when it comes to distribution of the Prasad. It again starts once the distribution is finished.

The ones who distributed the prashad now kneel before the dohor and the priest blesses them asking god to forgive them if they might have unknowingly distributed the prashads unequally. The dohor is then taken to the deuri's house in a procession accompanied by the drums, trumpet and taal. It is left in the court yard for the night in a similar platform as that near the Gohai ghar. It's high time for the villagers to get ready with the requirements for the puja as the dohor will be taken house to house the next day.

When the dohor is taken to a family the following song was sung in earlier days. The song, now no longer sung has been collected from one Late Kerani Rabha ( $80 \mathrm{yrs}$ ) by the researcher in the year 2012, a villager belonging to Bunbari, an adjacent Rabha village. It runs thus:

1. Hokol Phule Phule lutir bai aru phule tara narir kopalote henduror phot. (entry)

2. Kahi phule phule uri loi jai

3. O bai he enuwa korar mok tenuwa korare mok Aa kati kati rulung hali

4. Dui bhuila bhuila nari, narir kopalote henduror rekha musi di jabo kone.

5. Jangi kati kati rulung gui hiyake katibo kune

6. O mahi olai aa olai a a a hwiya ja ho hoiya petot asa toi kokra mokra hoiya

7. Gohai ghoror kathi kathi indure tule mati Gokhaniye bohi ase bogulare pakhi.

8. Aa aa jang aa olai aa.

The following four songs are sung during various stages of the offering. The songs have been collected from Dhanburi Rabha (80yrs) of 2 No. Kataligaon (Rabha supa) on $14^{\text {th }}$ of April, 2016.

1. Honar hala khati

Rupor pahi khati

Gohai jai alangot uthiye

$O$ di khawa rongmoni

$O$ biya diba lagewe

Rupor pahi khati

Gohai jai alangot uthiye.

2. Gohai ahe gohai ghorote

Ulai biya khang

Ami nari ebhageni hewa kari jang.

3. Gohai ahe rati

Gohai randhe api

Gohaike boraba japiye

O son puino boro tiko

Huna lore sore.

Gohai ahe rati

Gohai randhe ati

Gohaike boraba japiye 
4. Dhan tikuwa deurito puwa

Ui ram porat khang porat khang korewe

Rohe logori bhagaba paranai

Ui ram duklai khang duklai khang korewe

Bau dhan kekua deuritu khukuwa

Ui ram kol khang kol khang korewe

Ro he logori bhagaba paranai

Ui ram baklai khang baklai khang korewe

The above songs highlight the devotion of the village folk associated with their simple humorous life. The priest is also teased through the song that sings- the priest is greedy for he wants to eat even the banana peels.

With the sound of the drums every family that does the puja has to gear up as the dohor has already set on its way. The first house that the dohor goes to is to a family in the adjacent Bodo village. They had given up the puja with a final ritual wherein they threw a party for whole of the villagers. But the same year their son had gone blind and the family had seen misfortunes never seen before. They had to do the puja once again. Their blind son got his eyesight back but with a defect. He now suffers from night blindness and sees things very vaguely.

Earlier, there were two strong men who carried the drum from house to house, from village to village. One has now expired and the other has grown much weaker. And now it's the turn of the youngsters to carry the heavy drum. Everyone who follows the procession from house to house wears a loin cloth, gamcha with a bihuwan tied round the waist or thrown over the shoulder and round the neck. There are records of taking the dohor to far off villages and returning at midnight amidst heavy rain and storm. Every one following the procession struggles to keep up the pace while the ones who carry the drums and the dohor move with ease through the hardest rain. This is believed to be the power of Bura Bun Gohai.

As soon as the dohor reaches the family, they welcome everyone. The ones following the dohor make themselves comfortable in the already spread mat or bench while the dohor is tied to the rooted bamboo as done the previous day in front of the village Gohai ghar. The music comes to an end for sometime as the offerings are made to the Gohai. The family offers tea and rice beer to everyone present. Amongst the ones helping the priest known as deuri, some are entrusted to bring flowers along. When they bow to the Gohai, flowers are tucked into the ears of the worshippers and garlands are put round the head of the persons in whose names the puja is specially conducted and they also offer handkerchiefs in their names. The offerings are almost the same as that offered the previous day. Five 'donas' are placed on five 'aglotis'. Offerings are placed on this 'donas'. Bettle nut is also offered along with the offerings. The music of dhul, kahal and taal goes on while the deuri arranges the offerings and offers them to Bura Bun Gohai. The deuri's clear voice rings in the air, 'Joi aai Bura Bun Gohaik sinti hori bol, hori bol, hori bol.' And then everyone chants 'hori bol, hori bol, hori bol.' The rythm of the music and the tone of the kahal changes as the family members go round touching the feets of the village elders and receiving their blessings beginning with the deuri.

The blessings of a village elder known as Letra Bangali is still remembered by every member of the village. He is now no more. He was once a very strong man with the strongest legs in the whole area of Mushalpur, the district headquarters of Baksa. He could walk and walk and walk. He visited every haat in the whole surrounding areas as he was a pigeon seller and that too on foot. The young school goers struggled to keep pace with him as they had to tread along the same path beside him and they were too poor to own a cycle. They literally had to run. One peculiar thing about Letra Bangali is that his slippers always grew thinner at his heels and finally holes were cracked due to his habit of walking long distances. His prayer goes-

"He ai Bura Bun Gohai,

Ami je ei naung naung suli ketak loi

Ga dhui, gat jika kapur loi, ei rodot 


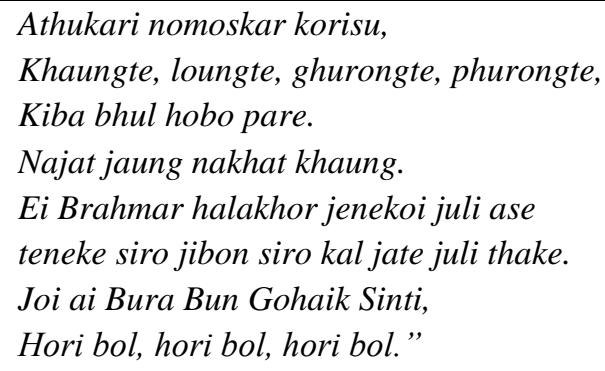

And the air rings with the sound of everyone young and old present, 'Hori bol, hori bol, hori bol.'

The translated version of Letra Bangali's blessings would be-

"O Mother Old Forest Goddess,

We, along these small small kids

Bathing, taking wet cloth on our body, in this hot sun

Bow to you kneeling.

While eating, while moving around

We might have committed mistakes.

We go where we are not supposed to, eat what we are not supposed to.

Just as the Brahma's wick

Is burning;

In the same way,

Let our life shine forever and ever.

Let's say, praise be Bura Bun Gohai, praise him, praise him, praise him."

When the offering in one house gets over, they move on to the next. The ones carrying the rice offered comes the last as they are still bargaining for more. The deuris go to the next house after doing their bit much before the actual puja is over. They don't take any alcohol as they have to go on offering prayers from house to house till nightfall. This is the first day of the puja and the dohor has to be taken to all the 75 houses in the villages. We can just imagine the conditions of the ones drinking local wine in more than 50 houses. Towards the time they reach the other end of the village, the village folk begins fighting with each other for no reason. This has now been a custom for it's almost incomplete without a fight. The fight, in most of the time, is harmless as the fighters are not left with any strength after taking so much of local wine without any food other than the prashad. Many times the procession is left with only a few members as most of the followers are in a state of hallucination much before they actually crossed the middle of the village.

The next day, the dohor is taken to the nearby villages. The Gohai now seems to be accepted by people from different communities. It is sometimes taken to a village called Laphakuchi, where the sister of Bura Bun Gohai is believed to be present. It's when entering the Gohai ghar of that village that the strongest man among the group holds the Dohor because it is a fact that the Dohor pulls back towards the altar when being taken out of the temple. A weak man would simply be dragged off backward.

The Dohor is taken to some other villages such as Sundarbari (Bwrimakha), Bunbari, Barbari, and Monokha.

After seven days, the final offerings are made to the Gohai and the handkerchiefs are removed ceremonially. The bamboo is now taken to the riverside in a procession and submerged in water, wherein all the others take bath and return to the Gohai ghar. It is believed that the one who throws the bamboo into the water has to dive in and that he sees strange images of devils and gods. And now the villagers are left without a mother. To fill the void, they gather in groups and go from house to house, drinking, feasting, and dancing. It's celebration time again. All this while there's no work to be done for it's the time to enjoy. 


\section{Conclusion}

It is seen that the Totola Rabhas have a very rich tradition of folklore, which has not at all been explored. They are passed down from generation to generation through word of mouth and in the long run, they have undergone a drastic change due to assimilation with people of other communities. This assimilation has enriched and added to the already existing folklore of the Totola Rabhas.

The religious folk songs of the Totola Rabhas are indeed unique in their own nature. The songs sung during various occasions are a living tradition of the Totola Rabhas. But the religious songs sung during the offerings to the Bura Bun Gohai are no longer sung in the real sense of the term. They are remembered only by a handful number of elderly people who turn to their memory to present the songs when asked to; it's been very long since they have last sung the songs. There are no documented perspectives and a lot more has to been done to explore and preserve the religious folk songs.

\section{References}

[1] Bhuyan, Paresh. (2015). Boro Kachari and Rabha Tribes of Assam. Boro Publication Board: Ghy

[2] Bora, Debabrat. (2013). "Rabha Janagosthir Dabiaru Rabha Hasong" in Prithak Rajyar Dabi: Asomar Janajati. Ghy: Sneha Prakashan Pp: 61-66

[3] Dalton, Edward Tuite. (1872). Descriptive Ethnology of Bengal. Calcutta: Office of the Superintendent of Government Printing, p. 87

[4] Gait, E.A. (1892). Census of Assam. Shillong: Assam Secretariat office

[5] Hakasam, Upen Rabha. (2015). Rabhamiz: Bhasa Aru Nidarshan. Ghy: Bina Library

[6] Hole, Christina. (1944-45). English Folklore. P. Vii. 